\title{
Breast-Conserving Therapy Versus Radical Mastectomy for Early Breast Cancer: 20-Year Follow-Up
}

Elena Alexandrova ${ }^{1 *}$, Sonya Sergieva ${ }^{2}$, Ana Saint Georges ${ }^{3}$, Dimiter Katsarov ${ }^{1}$, Margarita Taushanova ${ }^{4}$, George Kalaidjiev $^{1}$ and Angel Milev $^{1}$

${ }^{1}$ Department of Thoracic Surgery, National Oncological Hospital, Sofia, Bulgaria

${ }^{2}$ Department of Nuclear Medicine, Sofia Cancer Center Blvd, Sofia, Bulgaria

${ }^{3}$ Department of Surgery, Hospital Tokuda, Sofia, Bulgaria

${ }^{4}$ Department of Chemotherapy, Hospital Nadejda, Sofia, Bulgaria

\begin{abstract}
Purpose: The aim of this clinical study was to compare breast-conserving therapy (BCT) and radical mastectomy (RM) in the treatment of early breast cancer.

Materials and methods: From March 1986 to the end of 1989, 117 women with a breast tumor of up to 2 $\mathrm{cm}$ in size were included in this study; 66 women had a quadrantectomy, while 51 had a radical mastectomy. Full axillary dissection was performed in all patients, while adjuvant chemotherapy with cyclophosphamide, methotrexate and fluorouracil was conducted in node-positive patients. Radiation to the remaining breast parenchyma consisted of external-beam therapy, with or without regional irradiation, without boost to the tumor bed.

Results: The follow-up of patients in the two treatment groups was limited to 240 months. The mean period of observation ( $\mathrm{SD} \pm$ ) was 201.34 months $(54.12 \pm 226.5)$ for the patients with breast-conserving therapy (BCT) and 195.84 months $(35.1 \pm 226.5)$ for the patients with radical mastectomy. No significant difference in overall survival $(p=0.5410)$, distant metastases (Chi-Square tests, $p=0.117$ ) and contralateral breast cancers (ChiSquare Tests, $p=0.809$ ) between the two groups was established. The average survival for patients in both study groups was also statistically insignificant (211.4 months with $95 \%$ Confidence Interval $197.9 * 224.9$ in the quadrantectomy group and 204.0 months with 95\% Confidence Interval $188.0 * 219.9$ in the radical mastectomy group, Log Rank, $p=0.342$ ).
\end{abstract}

Conclusion: Our data support the view that breast-conserving surgery and irradiation is equivalent to mastectomy in terms of long-term survival for patients with stage I breast cancer.

Keywords: Breast cancer; 20-year follow-up; Conserving surgery; Radical mastectomy

\section{Introduction}

For almost a century, radical mastectomy, introduced by Halsted, was the method of choice for the treatment of breast cancer, despite the stage of the disease and the age of the woman. During that time period, the idea of breast conservation was highly unpopular and widely refuted. This sentiment was clearly expressed in the words of the famous surgeon Urban, who, during one of his lectures in front of the Society of Surgical Oncology in 1976, expressed regret that "the rational way of treating breast cancer is substituted by the woman's vanity." [1]. Currently, these beliefs are only of historical value. In the early 1990s, breast conservation surgery followed by radiotherapy was accepted as the standard treatment for early diagnosed tumors of the breast [2]. Dramatic changes occurred as a result of the immense amount of research conducted in oncological centres throughout Europe and North America. Numerous clinical studies comparing breast conservation approaches and radical mastectomy proved the same efficacy as far as overall survival was concerned [3-8]. The main argument for a critical valuation of the data was the fact that it was all preliminary due to the short follow-up period of patients. To prove the effectiveness of new treatment methods, patients with small tumors should be followed up for a long period of time, even for decades. The aim of this clinical study was to compare breast-conserving therapy (BCT) and radical mastectomy (RM) in the treatment of early breast cancer.

In 1986, a few years after research was initiated in Milan, the national oncological centre in Sofia began a study whose purpose was to note the long-term treatment results of performed quadrantectomy with post-operative radiotherapy. We closely followed 124 patients over a 20 -year period and are now reporting the latest results.

\section{Materials and Methods}

Patient recruitment in the study started in March 1986 and finished at the end of 1989 with the enrolment of 124 patients of up to 60 years of age with invasive breast tumors up to $2 \mathrm{~cm}$ in size $\left(\mathrm{T}_{1}\right)$ and a clinically negative axilla $\left(\mathrm{N}_{0}\right)$. Patients with in situ tumors, pregnant women, and women with a positive family history for breast cancer were not included in the study.

The clinical staging of the disease was performed in accordance with the TNM classification of the international union against cancer [9] (revision, corresponding to the year of the diagnosis was given). Seven patients $(8.68 \%)$ were excluded due to incorrect staging. The remaining 117 patients were divided into two types of surgical treatment methods: organ-sparing (66 patients) and mastectomy (51

*Corresponding author: Alexandrova E, Department of Thoracic Surgery, Nationa Oncological Hospital, Am Sportpark Müngersdorf 6, "Plovdivsko Pole" Street 6, Sofia 1756, Bulgaria, Tel: +359(2) 8076 234; E-mail: elenaalexandrova@mail.bg

Received December 14, 2015; Accepted September 27, 2016; Published Septembe 29, 2016

Citation: Alexandrova E, Sergieva S, Georges AS, Katsarov D, Taushanova M, et al. (2016) Breast-Conserving Therapy Versus Radical Mastectomy for Early Breas Cancer: 20-Year Follow-Up. J Cancer Sci Ther 8: 228-232. doi: 10.4172/19485956.1000418

Copyright: (C) 2016 Alexandrova E, et al. This is an open-access article distributed under the terms of the Creative Commons Attribution License, which permits unrestricted use, distribution, and reproduction in any medium, provided the original author and source are credited. 
patients). The distribution of the patients in the corresponding groups is shown in Figure 1.

The surgical treatment option of the patients in the organ-conserving group was classical quadrantectomy, as described by Veronesi [9]. The primary tumor was excised with an area of $2 \mathrm{~cm}$ to $3 \mathrm{~cm}$ of surrounding healthy parenchyma, with the underlying fascia of the large pectoral muscle and the overlying skin. A mandatory condition for conserving the breast was the achievement of tumor-free resection margins. In case of positive margins, partial resection was not performed, but the patient was redirected towards a radical mastectomy.

The patients from the radical mastectomy group were surgically operated according to the original Halsted method [10], which was used in 44 of the patients. Seven patients of that group had mastectomy performed using the method of Patey [11].

Following the treatment policy of the Centre during this time period, all 117 patients underwent axillary dissection. In the patients with medial tumor localization, a parasternal lymph node biopsy was performed for the purpose of disease staging.

The patients with quadrantectomy underwent radiation of the residual parenchyma with doses of up to $50 \mathrm{~Gy}$ without an additional dose in the tumor bed. Twenty-one patients with histologically proven metastatic lymph nodes received a radiation dose of $40 \mathrm{~Gy}$ to the lymph nodes in the region of mammaria internal and the supra clavicular lymph nodes.

Adjuvant chemotherapy was performed based on the pathological characteristics of the primary tumor. The main chemotherapy scheme used at the time was a combination of cyclophosphamide $100 \mathrm{mg} / \mathrm{m}^{2}$ taken per OS daily from the 1st to the 14 th day, methotrexate $40 \mathrm{mg} / \mathrm{m}^{2}$ and fluorouracil $600 \mathrm{mg} / \mathrm{m}^{2}$ intravenously on the $1 \mathrm{st}$ and the 8 th day, for a total of 6 courses. This scheme was applied to $21(31.8 \%)$ of the patients with quadrantectomy and in $13(25.4 \%)$ of the patients with radical mastectomy.

Adjuvant hormonal therapy was performed in 35 (53\%) of the patients with quadrantectomy and $26(50.1 \%)$ of the patients with mastectomy, based on the data obtained from hormone receptor studies.

Tamoxifen in a dose of $20 \mathrm{mg}$ daily was given for a period of 5 years. In young women with regular menstrual cycles, surgical castration and, less often, laser castration (in 9 patients) was performed before the administration of hormonal therapy with tamoxifen, following the treatment guidelines of the period.

The patients were monitored at a 4 month interval during the first two years after completion of the treatment and afterwards at a 6 month interval. The follow-up examination included a yearly clinical

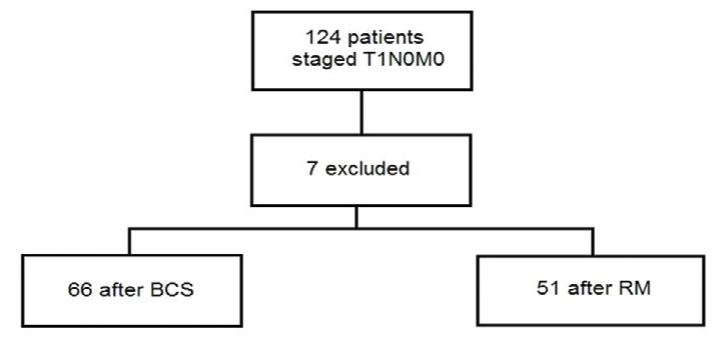

Figure 1: Patient's distribution to breast-conserving surgery (BCS) and radical mastectomy (RM).

\begin{tabular}{|c|c|c|c|}
\hline Characteristics & $\begin{array}{c}\text { Breast conserving } \\
\text { therapy } \\
(\mathrm{N}=66)\end{array}$ & $\begin{array}{l}\text { Mastectomy } \\
\quad(\mathrm{N}=51)\end{array}$ & $\begin{array}{c}P \\
\text { Value }\end{array}$ \\
\hline \multicolumn{3}{|l|}{$\begin{array}{l}\text { Age (at time of } \\
\text { diagnosis) }\end{array}$} & \multirow{3}{*}{0.666} \\
\hline$\leq 35$ years & $17(25.7 \%)$ & $11(21.6 \%)$ & \\
\hline$>35$ years & $49(74.3 \%)$ & $40(78.4 \%)$ & \\
\hline \multicolumn{3}{|l|}{ Menopausal status } & \multirow{3}{*}{0.703} \\
\hline Pre-menopausal & $26(39.4 \%)$ & $18(35.3 \%)$ & \\
\hline Post-menopausal & $40(60.6 \%)$ & $33(64.7 \%)$ & \\
\hline \multicolumn{3}{|l|}{$\begin{array}{l}\text { Axillary node } \\
\text { status }\end{array}$} & \multirow{3}{*}{1.000} \\
\hline No & $42(63.6 \%)$ & $33(64.7 \%)$ & \\
\hline $\mathrm{N}+$ & $24(36.4 \%)$ & $18(35.3 \%)$ & \\
\hline \multicolumn{3}{|l|}{ Histological kind } & \multirow{4}{*}{0.849} \\
\hline Invasive ductal & $42(63.7 \%)$ & $34(66.7 \%)$ & \\
\hline Invasive lobular & $17(25.7 \%)$ & $11(21.6 \%)$ & \\
\hline Others $^{*}$ & $7(10.6 \%)$ & $6(11.7 \%)$ & \\
\hline \multicolumn{3}{|l|}{ Grading } & \multirow{3}{*}{0.617} \\
\hline G2 & $22(33.3 \%)$ & $7(13.7 \%)$ & \\
\hline G3 & $44(66.7 \%)$ & $44(86.2 \%)$ & \\
\hline \multicolumn{3}{|l|}{ ER-status } & \multirow{5}{*}{1.000} \\
\hline Positive & $47(71.2 \%)$ & $37(72.5 \%)$ & \\
\hline Negative & $19(28.7 \%)$ & $14(27.4 \%)$ & \\
\hline Chemotherapy & $21(31.8 \%)$ & $13(25.4 \%)$ & \\
\hline Hormonal therapy & $35(53 \%)$ & $26(50.1 \%)$ & \\
\hline
\end{tabular}

Table 1: Patients' characteristics.

examination, mammogram, conventional lung X-Ray, abdominal ultrasound, and bone scintigraphy.

The main objective of this long-term analysis was to compare radical mastectomy and breast conserving therapy $(\mathrm{BCT})$ with respect to local recurrences, distant metastases and overall survival.

The major prognostic factors (age, menopausal status, axillary lymph-node status, histologic type, tumour grade, ER/PR status and adjuvant treatment) were compared using a chi- square test or Fisher's exact test [12].

Overall survival was estimated using the Kaplan-Meier method, and the obtained results of mastectomy and BCT were compared using the log-rank test [13].

\section{Results}

The average age $(\mathrm{SD} \pm)$ of the patients from the quadrantectomy group was $49.58 \pm 10.1$ years, while that of the radical mastectomy group was $48.55 \pm 8.4$ years, $(\mathrm{p}=0.666)$.

The maximum follow-up period for the patients from both groups was limited to 240 months. The average follow-up period (SD \pm ) of patients with quadrantectomy was 201.34 months (54.12 \pm 226.5$)$, and 195.84 months $(35.1 \pm 226.5)$ for patients with radical mastectomy. The main clinical and histological characteristics of patients from both treatment groups, resulting from the oncological condition, are shown in Table 1.

Comparison of the main prognostic indicators of patients from both treatment groups failed to find statistically significant differences in any of the aforementioned factors (chi-square test, $p>0.05$ ). This gives us reason to assume that patients from both monitored groups are similar and that the results of both administered treatment options can be correlated using the following measures: survival, local recurrences, 


\begin{tabular}{|c|c|c|c|c|c|}
\hline \multirow{2}{*}{ Event } & \multicolumn{2}{|c|}{ Breast-conserving treatment $(n=66)$} & \multicolumn{2}{|c|}{ Radical Mastectomy $(n=51)$} & \multirow{2}{*}{$P$ value } \\
\hline & Number of events & $\%$ & Number of events & $\%$ & \\
\hline Alive & 41 & $62.1 \%$ & 31 & $60.8 \%$ & 0.9426 \\
\hline Local relapse & 12 & $18.2 \%$ & 4 & $7.8 \%$ & 0.106 \\
\hline Distant metastases & 21 & $31.8 \%$ & 18 & $35.2 \%$ & 0.117 \\
\hline Contralateral breast carcinoma & 11 & $16.7 \%$ & 10 & $19.6 \%$ & 0.809 \\
\hline
\end{tabular}

Table 2: Incidence of events over the 20-year period within the two groups of patients.

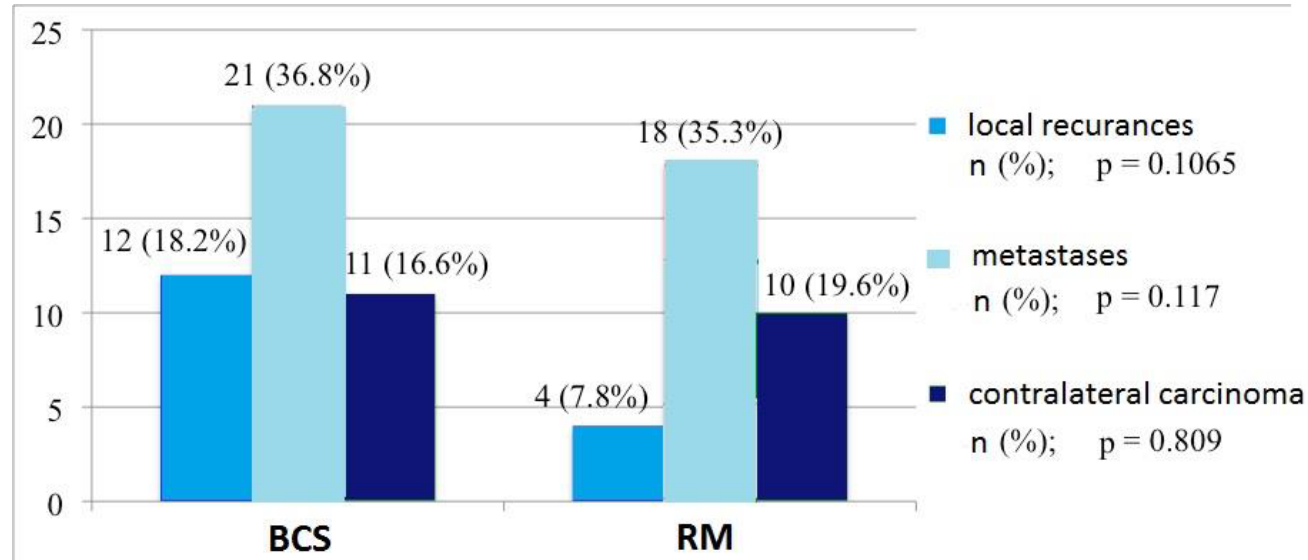

Figure 2: Incidence of local recurrence, distant metastases and contralateral breast carcinoma.

and distant metastasis. The treatment outcome for this disease after organ preservation and radical mastectomy is shown in Table 2 .

At the end of the 20-year follow-up period, the number of patients who were still alive was $62.1 \%$ of patients with quadrantectomy and $60.8 \%$ of patients with radical mastectomy $(p=0.9426)$. Twelve $(18.2 \%)$ local recurrences were found in the group with breast conserving surgery and $4(7.8 \%)$ in the group with radical mastectomy, $(p=0.1065)$. Other than the higher frequency of recurrence after quadrantectomy and radiation, there is no significant difference between the two treatment groups due to the small number of cases.

Eleven contralateral breast cancers $(16.6 \%)$ were found in the group with quadrantectomy versus $10(19.6 \%)$ in the group with radical mastectomy $(p=0.809)$ (Figure 2).

Chest wall recurrences after mastectomy arise relatively early on, with a mean period of 67.25 months after the treatment $(S D \pm 74.13)$. In addition, we noticed a very late onset of recurrences in the chest wall after a Halsted mastectomy, i.e., after 18 years. Our results failed to show any significant differences between local recurrences, distant metastases and contralateral carcinoma, which results in the observed survival. Recurrences appeared in the residual parenchyma throughout the whole follow-up period, with a post-operative average of 74.79 months ( $\mathrm{SD} \pm 60.57)$.

The recurrence distribution in the quadrants of the breast shows that in only 5 (41.6\%) of the cases, the recurrence was localized in close proximity to the operative cicatrices. These recurrences arose early after treatment completion, with an average of 37.45 months' post treatment, and tended to manifest as diffuse growths or skin infiltrations.

The remaining seven recurrences $(58.4 \%)$ were located in places further away from the infiltrated quadrant. They arose significantly later on, with an average of 98.79 months after treatment, and their occurrence was noted after the tenth and fifteenth years following the end of therapy. All recurrences of the chest wall were confined to the surgical cicatrix and the proximal flap. Everything were locally operable, but one was multiple. Development of distant metastases was observed in almost the same number of patients from both comparison groups: 21 patients (36.8\%) from the group with quadrantectomy and 18 patients $(35.3 \%)$ from the group with radical mastectomy (Chisquare tests $p=0.117$ ). Furthermore, the average period of time for the development of distant metastases in the two groups did not differ significantly (69 months in patients from the quadrantectomy group and 63 months in patients from the radical mastectomy group (Chisquare tests $p=0.755$ ).

The distribution of the distant metastases in all 117 patients, and thus from both treatment groups, as based on organ site is as follows: bones in 16 patients (13.7\%), lungs in 13. patients (11.1\%), the liver in 5 patients $(4.3 \%)$, the pericardium in 1 patient $(0.8 \%)$, and multiple metastases noted simultaneously in the lung, brain, pleura and bones in 11 patients (9.4\%). The frequency of contralateral tumors in the two treatment groups was also similar: $11(16.6 \%)$ in the organ-sparing group and $10(19.6 \%)$ in the radical mastectomy group (chi- square test, $p=0.809$, Figure 2 ). The median overall survival did not differ significantly between the two groups (211.4 months with a 95\% CI 197.9-224.9 months in the organ-sparing treatment group and 204.0 months with $95 \%$ CI 188.0 to 219.9 months in the radical mastectomy group, Log rank $p=0.759$ ) (Table 3 ).

The survival functions, compared using the Kaplan-Meier method, do not detect a significant difference between patients with organ preservation and those with radical mastectomy. Patients were followed for 240 months after the completion of therapy (Log rank test $p=0.5410$ ) (Figure 3).

A 20 -year survival was noted in $56 \%$ of the group with radical mastectomy and $58 \%$ of the group with breast-conserving treatment $(p=0.5410)$. 


\begin{tabular}{|c|l|l|l|l|}
\hline Treatment Groups & AS* (Months) & SE (Months) & $\mathbf{9 5 \%}$ Cl (Months) & Observation Period (Months) \\
\hline Breast-conserving treatment & 211.4 & 6.890 & $197.9-224.9$ & 240 \\
\hline Radical mastectomy & 204.0 & 8.142 & $188.0-219.9$ \\
\hline AS* Average Survival, SE-standard error, Cl-Confidence Interval \\
\hline
\end{tabular}

Table 3: Average survival after breast conserving treatment (BCT) and radical mastectomy (RM).

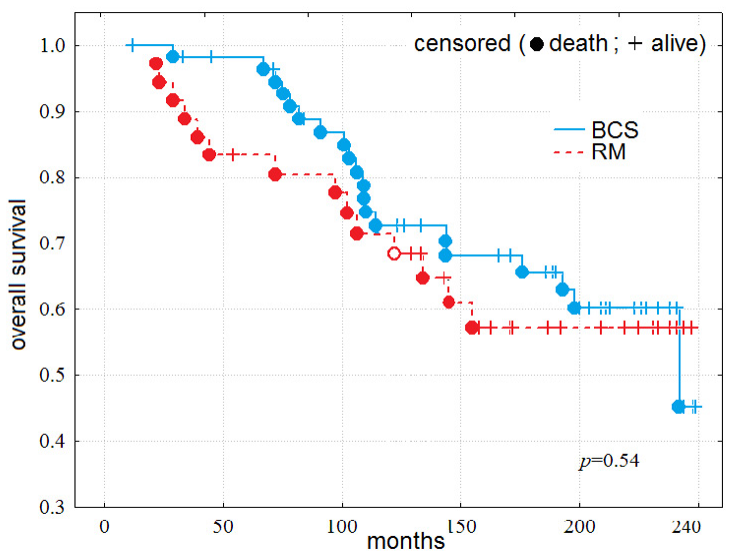

Figure 3: Overall survival of patients followed for 20 years after breast conserving surgery (BCS) and radical mastectomy (RM).

\begin{tabular}{|c|c|c|c|}
\hline Clinical studies & $\begin{array}{c}\text { Breast-conserving } \\
\text { treatment }\end{array}$ & Radical mastectomy & $\begin{array}{c}\boldsymbol{P} \\
\text { value }\end{array}$ \\
\hline Milan-I [14] & $60.8 \%$ & $62.1 \%$ & 1.0 \\
\hline NSABP B- 06 [15] & $46 \%$ & $47 \%$ & 0.67 \\
\hline DBCG-82TM [16] & $53.7 \%$ & $49.1 \%$ & 0.24 \\
\hline EORTC [17] & $39.1 \%$ & $44.5 \%$ & 0.42 \\
\hline NCC- Sofia & $56 \%$ & $58 \%$ & 0.54 \\
\hline
\end{tabular}

Table 4: Overall survival rate after BCT and RM in studies with a 20-year followup period.

\begin{tabular}{|c|c|c|}
\hline Studies & Type of local treatment & $\begin{array}{c}\text { Frequency of local } \\
\text { recurrences }\end{array}$ \\
\hline Milano-I [14] & $\begin{array}{c}\text { quadrantectomy with radiation therapy } \\
50+\text { +overdose 10 Gy }\end{array}$ & $8.8 \%$ \\
\hline $\begin{array}{c}\text { NSABP-B06 } \\
\text { [15] }\end{array}$ & $\begin{array}{r}\text { Tumorectomy with radiation therapy } \\
50 \mathrm{~Gy}\end{array}$ & $14.3 \%$ \\
\hline $\begin{array}{c}\text { EORTC 10801 } \\
{[16]}\end{array}$ & $\begin{array}{c}\text { lumpectomy, radiation therapy and } 25 \\
\text { Gy additional dose }\end{array}$ & $20 \%$ \\
\hline $\mathrm{NCI}[17]$ & $\begin{array}{r}\text { a wide local excision and radiation } \\
\text { therapy dose 50 Gy }\end{array}$ & up to $22 \%$ \\
\hline $\mathrm{NCC}-$ Sofia & $\begin{array}{r}\text { quadrantectomy with radiation therapy } \\
\text { dose } 50 \text { Gy }\end{array}$ & $18.2 \%$ \\
\hline
\end{tabular}

Table 5: Frequency of local recurrences after organ-preserving therapy in patients followed for 240 months.

\section{Discussion}

The results from this study demonstrate the same overall survival rates for women with an early stage of breast cancer, whether treated with quadrantectomy and post-operative radiation therapy or with radical mastectomy $(p=0.5410)$. Our standpoint is based on the results collected over a span of 20 years, along with data obtained by other well-known research studies, published after the year 2002 (Table 4).

The closest correlation was found with the latest Milan-I [14] data (60.8\%, versus $62.1 \%, p=0.9$ ), which is most likely due to incorporating the same criteria for patients along with using the same surgical methods for the treatment of the primary tumor (quadrantectomy and radical mastectomy using the Halsted method). Our latest overall survival results are comparable to the most extensive data-based comparison study conducted, that is, The national surgical adjuvant breast and bowel project (NSABP B-06) [15]. Although in that study, lumpectomy and radiation therapy are compared to a modified radical mastectomy, the twenty-year survival rate of both groups was statistically the same ( $46 \%$ in the group with lumpectomy and radiation therapy versus $47 \%$ in the group with modified mastectomy, $p=0.67)$. Similar findings were also noted in the latest results of the DBCG-82TM protocol [16] ( $53.7 \%$ in the conservative group versus $49.1 \%$ in the mastectomy group, $p=0.24$ ) and further proven by the data from the European organization for research and treatment of cancer (EORTC) 10801 ( $39.1 \%$ versus $44.5 \%, p=0.42)$.

All of the aforementioned well-known studies, as well as the present study, show the same overall survival rate in patients treated with either of the two different local methods, despite the different criteria incorporated or the elected treatment procedure. Therefore, the results of the current study support the main viewpoint for systemic therapy and the fact that the prognosis of breast cancer is linked to the presence or the absence of occult foci arising from metastatic cells, not from the local treatment option. The results of this study provide additional evidence that the preservation of the breast does not negatively alter patient survival and contribute to the elimination of existing doubts in regards to the effectiveness of organ preservation methods. The frequency of local recurrences in our study is comparable with the results of other studies with a 20-year follow-up period [14-17] (Table 5).

The close correlation in the frequency of local recurrences after a quadrantectomy and 50 Gy post-operative radiation (18.2\%) and a contralateral tumor in this group (16.7\%) supports the view that some part of the recurrences in the residual parenchyma are not the result of a residual tumor but rather a congenital tendency in developing breast cancer. The differences in cumulative frequency of local recurrences is due to the different criteria used for the incorporation of patients, the different surgical procedures utilized, and the treatment dose used in the different studies. Our data confirm the proposition that the residual parenchyma after organ-preserving resections has the potential for the development of local recurrence; that is, organ-preserving operations are associated with a higher frequency of local recurrences (12 in the residual parenchyma versus 4 in the chest wall).

In our patients, recurrences in the residual parenchyma completely correlate with the model, which has been described in great detail by the researchers of IGR [8], who were the first to describe the effect of prolonged follow-up of patients with breast-conserving treatment. After a 26-year follow-up of patients with organ-preserving operations, these researchers proved that there is no real stabilization of the risk of recurrence, as is observed in patients with mastectomy.

Our data also demonstrate that recurrences after a quadrantectomy can and do develop throughout the entire follow-up period, while recurrences in the chest wall after a radical mastectomy usually occur in the first three years (up to the 31st month). The long-term follow-up of patients gives us the unique opportunity to also observe exceptions, as in the case of recurrence in the chest wall, which arose 18 years (216 months) after a Halsted mastectomy. 
The similarities in the frequency of distant metastases in the two treatment groups (36.8\% in the quadrantectomy group versus $35.2 \%$ in the radical mastectomy group, $p=0.117)$ and the undifferentiated period of time it takes for their appearance ( 63 months for the recurrences in the chest wall and 69 months for the recurrences in the residual parenchyma, $p=0.755$ ) show that dissemination is a process that occurs and develops in the same manner, despite the local treatment plan implemented.

An important clinical conclusion drawn from the current study is the absence of an oncogenic effect from the conducted radiation therapy. It is widely known that one of the arguments against breast preservation has been the idea that a significant ionizing radiation dose, which destroys the residual tumor cells, could lead to a neoplastic transformation in the normal cells of the residual breast tissue and in the contralateral breast. If we accept the notion that during postoperative radiation of the residual parenchyma, the contralateral breast receives a radiation dose of $0.5 \mathrm{~Gy}$ in its most lateral portion and 10-15 Gy in the medial portion, then we can expect a drastic increase in the contralateral cancers in the group with organ- preservation treatment.

The similarity in the frequency of contralateral tumors between the group with organ-preservation treatment and that with radical mastectomy $(16.7 \%$ vs $19.6 \%, p=0.809)$ suggests the idea that the implemented radiation dose does not have a carcinogenic effect. Similar conclusions have also been reported by other authors who, after a 20-year study, have not found sufficient proof for radiationinduced carcinoma $[18,19]$.

Despite a few limitations connected with the retrospective character of the study and the small number of patients, our results are statistically significant due to the homogeneity of the groups and the strict criteria used to include the patients. This permits us to report our conclusions.

\section{Conclusions}

A twenty-year follow-up study of our patients proves that the organ-preservation procedures, which provide patients with a high quality of life, are a sure and safe method for early breast cancer treatment. Furthermore, the residual parenchyma is a potential place for the development of local recurrences, which requires the patients to be followed for decades or even throughout their remaining lives.

\section{References}

1. National Institutes of Health (1991) Consensus Development Panel Consensus Statement Treatment of early- stage breast cancer. JAMA 265: 391-395.

2. Sarrazin D, Lê MG, Arriagada R, Contesso G, Fontaine F, et al. (1989) Tenyear results of a randomized trial comparing a breast conservation therapy to mastectomy in early breast cancer. Radiother Oncol 14: 177-184.
3. van Dongen JA, Bartelink $H$, Fentiman IS, Lerut $T$, Mignolet $F$, et al. (1987) Randomized clinical trial to assess the value of breast conserving therapy in stage I and II breast cancer (trial 10801) EORTC. Breast Cancer Cooperative Group, 4th Working Conference.

4. Veronesi U, Natale C, Mariani L, Marco G, Saccozzi R, et al. (2002) Twentyyear follow-up of a randomized study comparing breast-conserving surgery with radical mastectomy for early breast cancer. N Engl J Med 347: 1227-1232.

5. Arriagada R, Le MG, Rochard F, Contesso G (1996) Conservative treatment versus mastectomy in early breast cancer: patterns of failure with 15 years of follow-up data. Institut Gustave Roussy Breast Cancer Group. J Clin Oncol 14 1558-1564.

6. Blichert-Toft M, Rose C, Andersen JA, Overgaard M, Axelsson CK, et al. (1992) Danish randomized trial comparing breast conservation therapy with mastectomy: six -years of life-table analysis. Danish Breast Cancer Cooperative Group. J Natl Cancer Inst Monogr 11: 19-25.

7. Fisher B, Anderson S, Brayant J, Margolese GR, Deutch M, et al. (2002) Twenty-year follow-up of a randomized trial comparing total mastectomy, lumpectomy, and lumpectomy plus irradiation for the treatment of invasive breast cancer. N Engl J Med 347: 1233-1241.

8. Hermaneck P, Sobin LM (1987) TNM classification of malignant tumors (4thedtn), International Union Against Cancer, Springer-Verlag, Berlin.

9. Veronesi U, Del Vecchio M, Luini A, Rasponi A, Zuccali R (1983) The quadrantectomy, axillary dissection and radiotherapy (QUART) technique in early breast cancer. Int Adv Surg Oncol 6: 141-165

10. Urban JA (1976) Changing patterns of breast cancer: Lucy Wortham James lecture (clinical). Cancer 37: 111-117.

11. Halsted W (1894) The results of operations for the care of cancer of the breas performed at the Johns Hopkins hospital from June, 1889, to January, 1894 Ann Surg 20: 497-555.

12. Kaplan EL, Meier P (1958) Nonparametric estimation from incomplete observations. J Am Stat Assoc 53: 457-481.

13. Fisher RA (1954) Statistical Methods for Research Workers. Oliver and Boyd Edinburgh.

14. Veronesi U, Orrecchia R, Luini A, Galimberti V, Zurrida S, et al. (2010) Intraoprative radiotherapy during breast conserving surgery: a study on 1,822 cases treated with electrons. Breast Cancer Res Treat 124: 141-151

15. Litiere S, Werutsky G, Fentiman SI, Rutgers E, Cristiaens MR, et al. (2012) Breast conserving therapy versus mastectomy for stage I-libreast cancer: 20 year follow-up of he EORTC10801 phase 3 randomized trial. Lancet Onco 13: $412-419$

16. Poggi MM, Danforth DN, Sciuto LC, Smith SL, Steinberg SM, et al. (2003) Eighteen-year results in the treatment of early breast carcinoma with mastectomy versus breast conservation therapy: The National Cancer Institute Randomized Trial. Cancer 98: 697-702

17. Stefanik D, Goldberg R, Byme P (1985) Locoregional failure in patients treated with adjuvant chemotherapy for breast cancer. J Clin Oncol 3: 660-665.

18. Sykes HF, Sim DA, Wong CL (1989) Locoregional recurrence in breast cance after mastectomy and adriamycin-based adjuvant chemotherapy: Evaluation of the role of post mastectomy radiation. Int J Radiat Oncol Biol Phys 16: 641-647 